\title{
Guiding Goal-Directed Therapy
}

\author{
Koichi Suehiro $\cdot$ Alexandre Joosten • \\ Brenton Alexander $\cdot$ Maxime Cannesson
}

Published online: 14 August 2014

(C) Springer Science + Business Media New York 2014

\begin{abstract}
Several studies have demonstrated that perioperative hemodynamic optimization (or "goal directed therapy") using minimally invasive hemodynamic monitoring technologies has the ability to improve postoperative patients' outcome with lower complication rates, shorter hospital lengths of stay, and lower cost of surgery. This specific concept of goal-directed therapy (GDT) uses perioperative cardiac output monitoring and manipulation of physiologic parameters (dynamic parameters of fluid responsiveness) to guide intravenous fluids and inotropic therapy with the goal of ensuring adequate tissue perfusion. Recently, the evidence related to the implementation of GDT strategies has been considered strong enough to allow for the creation of national recommendations in the UK, in France, and by the European Society of Anaesthesiology. The aims of the programs are to apply best practices to high-risk surgical patients and requires the participation of all clinicians involved in patients' care. Considering the potential clinical and economic benefits of GDT protocols and the positive recommendations from influential scientific societies, more and more hospitals around the world have become interested in implementing hemodynamic optimization in their departments. This review provides the information about the evolution of hemodynamic monitoring from invasive to the more recent noninvasive devices, and how these devices can be used in the operating rooms through well-defined algorithms of GDT.
\end{abstract}

K. Suehiro · A. Joosten · B. Alexander · M. Cannesson ( $\square)$ Department of Anesthesiology and Perioperative Care, University of California, Irvine, $101 \mathrm{~S}$ City Drive, Orange, CA 92868, USA

e-mail: mcanness@uci.edu
Keywords Goal-directed therapy · Cardiac output · Fluid responsiveness $\cdot$ Stroke volume

\section{Introduction}

It is estimated that approximately 240 million anesthesia procedures are performed annually around the world [1]. Of these, approximately $10 \%(\approx 24$ million $)$ are conducted on "high risk" patients. This subset disproportionally accounts for more than $80 \%$ of the overall mortality related to surgery [2]. Moderate risk surgery is much more common and represents approximately $40 \%$ of the entire annual surgical population (96 million patients a year). Thankfully, most of these patients continue on to have an uncomplicated postoperative course. However, it is estimated that approximately $30 \%$ of these $(\approx 29$ million patients a year) present with a "minor" postoperative complication, most commonly a gut injury inducing delayed enteral feeding, abdominal distension, nausea, vomiting, or wound complications [3]. Even if these complications are said to be "minor," they still lead to increased postoperative treatment, a longer length of stay and an overall increase in the cost of the medico-surgical management. A recent international, prospective assessment of surgical outcomes ("EUSOS" study) in non-cardiac surgical patients demonstrated that the mortality rate was high (4\%) and varied substantially across European countries, suggesting the need for national and even international guidelines to improve postoperative outcomes [4]. As above, we currently know that in most of these patients the postoperative complications are related to tissue hypoperfusion $[3,5]$. Thus, one of the most important goals of the physician anesthesiologist in the operating room (OR) is to maintain proper tissue perfusion through 
the optimization of intravascular volume status and stroke volume. To achieve that goal, as stated by Arthur Guyton in his Textbook of Medical Physiology, one needs "an adequate perfusion pressure in order to force blood into the capillaries of all organs and an adequate cardiac output (CO) to deliver oxygen and substrates, and to remove carbon dioxide and other metabolic products" [6, 7]. However, while blood pressure monitoring is part of the American Society of Anesthesiologists (ASA) guidelines for basic monitoring [8], $\mathrm{CO}$ is rarely monitored, even during high-risk surgery [9]. Fluid therapy in the OR has traditionally been guided by basic static parameters such as heart rate, blood pressure, urine output, peripheral oxygen saturation, and central venous pressure (CVP). Unfortunately, these variables have been shown to be poor predictors of intravascular volume or changes in $\mathrm{CO}$ in response to a volume expansion. Newer dynamic parameters relying on cardio-pulmonary interactions in patients under general anesthesia and mechanical ventilation have been developed and have consistently been shown to be superior to static parameters for the prediction of fluid responsiveness (defined as the percent change in stroke volume induced by volume expansion). These dynamic variables can be obtained using multiple modalities ranging from the more invasive arterial pressure waveforms $[10$, 11] to more recently available noninvasive approaches [12-14]. A large variety of CO monitoring devices are currently offered today that claim to allow for perioperative hemodynamic optimization. These technologies have rapidly evolved from very invasive to mini-invasive and even completely noninvasive devices. Despite such advances, clinicians are still unsure about how and which technology to use in their daily practice.

We should all keep in mind that such hemodynamic monitoring systems are simply measurement tools and to quote Dr. Michael Pinsky: "no monitoring device, no matter how simple or sophisticated, will improve patients' outcome unless coupled to a treatment which itself improves outcome" [15]. All these minimally invasive CO monitoring devices have the ability to improve postoperative patients' outcome with lower complication rates, shorter hospital lengths of stay, and lower cost of surgery [16-19] if they are integrated into appropriate protocols that guide the therapeutic interventions. This specific concept of goal-directed therapy (GDT) uses manipulation of physiologic targets to guide intravenous fluids and inotropic therapy with the goal of improving $\mathrm{CO}$ and oxygen delivery and thus preventing tissue oxygen debt by maintaining adequate tissue perfusion. As $\mathrm{CO}$ is a critical component of tissue oxygen delivery, any monitoring device used to guide therapy ideally should measure $\mathrm{CO}$. Beyond this, different devices and protocols emphasize the multiple components of GDT to varying degrees with no set conclusion on the ideal approach.
Table 1 Complications associated with hypervolemia and hypovolemia

\begin{tabular}{|c|c|}
\hline Complications of Hypervolemia & Complications of Hypovolemia \\
\hline $\begin{array}{l}\text { Increases venous pressure } \\
\text { resulting in loss of fluid from } \\
\text { the intravascular to interstitial } \\
\text { space which can lead to } \\
\text { pulmonary and peripheral } \\
\text { edema impairing tissue } \\
\text { oxygenation }\end{array}$ & $\begin{array}{l}\text { Reduces effective blood } \\
\text { circulatory volume resulting in } \\
\text { diversion of blood flow from } \\
\text { non-vital organs (skin, gut, } \\
\text { kidneys) to vital organs (heart } \\
\text { and brain) }\end{array}$ \\
\hline $\begin{array}{l}\text { Increases demand on cardiac } \\
\text { function }\end{array}$ & $\begin{array}{l}\text { Activates the sympathetic } \\
\text { nervous and renin angiotensin } \\
\text { system }\end{array}$ \\
\hline $\begin{array}{l}\text { Decreases tissue oxygenation } \\
\text { with delayed wound healing }\end{array}$ & Increases inflammatory response \\
\hline $\begin{array}{l}\text { May cause coagulation } \\
\text { disturbances through } \\
\text { hemodilution }\end{array}$ & $\begin{array}{l}\text { May also lead to vasopressor } \\
\text { agent administration which } \\
\text { may increase hypoperfusion } \\
\text { and ischemia [127] }\end{array}$ \\
\hline $\begin{array}{l}\text { Is associated with increased daily } \\
\text { fluid balance and mortality } \\
\text { [128]. Chappell et al. [129] also } \\
\text { demonstrate a relationship } \\
\text { between weight gain related to } \\
\text { excessive fluid administration } \\
\text { and mortality }\end{array}$ & \\
\hline
\end{tabular}

Recently, GDT evidence has been considered strong enough to allow for the creation of national recommendations in the UK, in France, and by the European Society of Anaesthesiology [20-22]. GDT has been recognized as the standard of care in the anesthesiology setting because it has demonstrated strong clinical evidence and benefit in reducing rates of postoperative complications. Despite these favorable results, widespread implementation of GDT has not yet been accomplished and this approach has been poorly adopted in clinical practice $[9,23]$. In many cases, fluids are still administered without appropriate goals or monitoring and most physician anesthesiologists use a combination of empirical formulas and fixed-volume calculations to guide their fluid therapy. This can lead to adverse clinical outcomes related to either hypovolemia or hypervolemia (Table 1). Both of these complications can potentially cause a decrease in oxygen delivery to the tissues which can then lead to an increase in postoperative morbidity (Fig. 1) [12]. As with most novel treatment strategies, there have also been studies arguing that GDT in high-risk surgery has no statistically significant benefit when compared to restrictive crystalloid administration $[24,25]$. In a recent randomized clinical trial in high-risk patients undergoing major abdominal surgery, GDT did not reduce postoperative complications and 30-day mortality [26••]. As more evidence concerning various clinical situations arises, the clinical settings most likely to benefit from GDT will be better elucidated. 


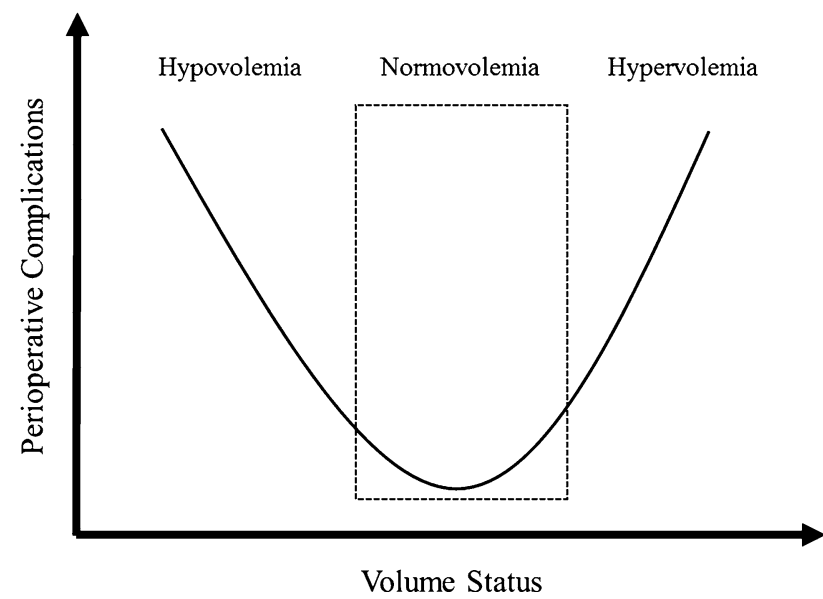

Fig. 1 The classic relationship between perioperative volume status and perioperative complications. The relationship describes a "U" shape with an increased risk of complication for both perioperative hypovolemia and perioperative hypervolemia, emphasizing the importance of perioperative fluid optimization

Progression toward a more standardized approach for proper fluid managements has been made in recent years. Most notably, official recommendations have been published in the UK (Enhanced Recovery Partnership), France (French Society of Anesthesiology), other European countries [Enhanced Recovery After Surgery Society (ERAS)] $[22,27]$, and in the United States [Perioperative Surgical Home (PSH) concept] [28]. In the UK, the National Health Service (NHS) has even created financial incentives to ensure hospitals implement hemodynamic optimization as standard of care for at least $80 \%$ of eligible patients. The aim of the ERAS program is to apply best practices to highrisk surgical patients and requires the participation of all clinicians involved in patients' care. In the United States, the PSH model has recently gained momentum as a "patientcentered" and "team-based" approach that guides the patient through the entire surgical procedure by developing protocols and guidelines to improve perioperative management with the physician anesthesiologist playing a central management role. The ultimate goal of a proper PSH system is a better coordination of care that employs increased standardization in order to reduce the variability between clinicians. This PSH design may soon become the standard of care in the US as it has been shown to result in improved clinical outcome $[28,29]$. Considering the potential clinical and economic benefits of GDT protocols and the positive recommendations from influential scientific societies, more and more hospitals around the world have become interested in implementing hemodynamic optimization in their departments.

This review will be divided into three main portions. In the first, we will describe the evolution in the choice of monitors used to perform GDT, most notably a move away from pulmonary artery catheters toward minimally invasive and even totally noninvasive monitors of $\mathrm{CO}$. As each of these devices calculate $\mathrm{CO}$ differently, we will quickly describe their main characteristics and limitations that should be considered when implementing clinical decisions making. In the second portion, we will analyze how these various devices have been used in the ORs through welldefined algorithms of GDT (depending on the types of surgery) and how it has impacted patient outcome. Lastly, we will describe the newer closed-loop GDT concept and see if it could be the future for applying GDT automatically.

\section{Monitoring for Guiding GDT in the Operating Room}

Anesthesiologists still use the traditional hemodynamic variables (heart rate, blood pressure, CVP, and urine output) to guide their perioperative fluid therapy. However, they have consistently been shown to be neither sensitive nor specific for evaluating fluid status as the signs of hypovolemia including tachycardia, hypotension, and oliguria may be present in euvolemia and absence during hypovolemia. In addition, Le Manach et al. [30] recently revealed that blood pressure (BP) changes could not be used to track stroke volume changes induced by volume loading. They also demonstrated that the relationship between arterial pressure, ventricular stroke volume, and venous return is not simple and certainly not linear. Consequently, $\mathrm{CO}$ optimization in the OR (which relies heavily on the idea that fluid administration increases venous return) cannot be adequately performed with monitoring only arterial pressure. Studies analyzing GDT have involved a variety of $\mathrm{CO}$ monitoring devices but none has been widely adopted for routine use. Hence, we should keep in mind that a variety of factors (institutional, device related, cost, experience, severity of diseases, heart rhythm, type of interventions, degree of invasiveness, safety, personal convenience, adaptability, etc.) influence the selection of a $\mathrm{CO}$ monitoring device in our current clinical practice. Thus, it is critical that clinicians understand each approaches underlying technical principles and inherent limitations. Generally, GDT is easier to implement with the newer technologies because they require less training and, in most cases, are more easily interpreted by the majority of clinicians. When assessing the reliability and clinical use of a noninvasive $\mathrm{CO}$ device, 2 factors are important: the accuracy of individual measurements compared with the reference method and the ability to track dynamic changes in $\mathrm{CO}$ accurately after a therapeutic intervention.

As demonstrated in a meta-analysis by Peyton [31], most of the available technologies (pulse contour 
Table 2 Available hemodynamic monitoring systems; advantages and limitations

\begin{tabular}{|c|c|c|c|c|c|c|}
\hline & System & Technology & Advantages & Disadvantages & Setting & GDT \\
\hline \multirow{6}{*}{$\begin{array}{l}\text { Invasive } \\
\text { Monitoring }\end{array}$} & \multirow[t]{2}{*}{ Vigilance } & \multirow{2}{*}{$\begin{array}{l}\text { Pulmonary artery } \\
\text { catheter }\end{array}$} & Gold standard for $\mathrm{CO}$ monitoring & Invasive system & \multirow{2}{*}{$\begin{array}{l}\text { OPE, } \\
\text { ICU }\end{array}$} & \multirow[t]{2}{*}{+} \\
\hline & & & $\begin{array}{l}\text { Allows measurements of } \mathrm{SvO}_{2} \text { and } \\
\text { pulmonary artery pressure }\end{array}$ & $\begin{array}{l}\text { No dynamic variables for fluid } \\
\text { responsiveness }\end{array}$ & & \\
\hline & \multirow[t]{2}{*}{$\mathrm{PiCCO}$} & \multirow[t]{2}{*}{ Calibrated PCA } & Continuous $\mathrm{CO}$ monitoring & \multirow{2}{*}{$\begin{array}{l}\text { Invasive system requiring a specific } \\
\text { femoral artery catheter }\end{array}$} & \multirow[t]{2}{*}{ ICU } & \multirow[t]{2}{*}{-} \\
\hline & & & $\begin{array}{l}\text { Allows measurement for } \mathrm{ScvO}_{2} \text { with } \\
\text { specific device }\end{array}$ & & & \\
\hline & \multirow{2}{*}{$\begin{array}{l}\text { Volume } \\
\text { view }\end{array}$} & \multirow[t]{2}{*}{ Calibrated PCA } & Continuous $\mathrm{CO}$ monitoring & \multirow{2}{*}{$\begin{array}{l}\text { Invasive system requiring a specific } \\
\text { femoral artery catheter }\end{array}$} & \multirow[t]{2}{*}{ ICU } & \multirow[t]{2}{*}{-} \\
\hline & & & $\begin{array}{l}\text { Allows measurement for } \mathrm{ScvO}_{2} \text { with } \\
\text { specific device }\end{array}$ & & & \\
\hline \multirow[t]{8}{*}{$\begin{array}{c}\text { Less-invasive } \\
\text { monitoring }\end{array}$} & $\begin{array}{l}\text { LiDCO } \\
\text { plus }\end{array}$ & Calibrated PCA & Continuous $\mathrm{CO}$ monitoring & Not enough validation studies & ICU & + \\
\hline & $\begin{array}{l}\mathrm{LiDCO} \\
\text { rapid }\end{array}$ & $\begin{array}{l}\text { Non-calibrated } \\
\text { PCA }\end{array}$ & $\begin{array}{l}\text { Continuous CO monitoring } \\
\text { Less-invasive and self-calibration }\end{array}$ & Not enough validation studies & $\begin{array}{l}\text { OPE, } \\
\text { ICU }\end{array}$ & - \\
\hline & Vigileo- & Non-calibrated & Continuous $\mathrm{CO}$ monitoring & Requires a specific sensor & OPE, & + \\
\hline & FloTrac & PCA & Less-invasive and self-calibration & Impacted by vascular motor tones & $\mathrm{ICU}$ & \\
\hline & PRAM & Non-calibrated & Continuous $\mathrm{CO}$ monitoring & Requires a specific sensor & OPE, & - \\
\hline & & PCA & Less-invasive and self-calibration & Not enough validation studies & $\mathrm{ICU}$ & \\
\hline & Pulsioflex & Non-calibrated & Continuous $\mathrm{CO}$ monitoring & No validation study & OPE, & - \\
\hline & & PCA & Less-invasive and self-calibration & & ICU & \\
\hline \multirow{12}{*}{$\begin{array}{l}\text { Non-invasive } \\
\text { monitoring }\end{array}$} & Nexfin & Non-calibrated & Continuous $\mathrm{CO}$ monitoring & Motion artifact & OPE & - \\
\hline & & & Non-invasive and self-calibration & Not enough validation studies & & \\
\hline & Cardiac Q & Ultrasound & Less invasive than PCA systems & Requires frequent adjustment for & OPE & + \\
\hline & & & Rapid application of the technique & 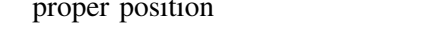 & & \\
\hline & USCOM & Ultrasound & Non-invasive $\mathrm{CO}$ monitoring & Not enough validation studies & OPE & - \\
\hline & NICOM & Bioreactance & Non-invasive CO monitoring & Not enough validation studies & OPE & + \\
\hline & ECOM & Bioimpedance & Less invasive than PCA systems & Not enough validation studies & OPE & + \\
\hline & BioZ & Bioimpedance & Non-invasive CO monitoring & Negative results in ICU patients & $\begin{array}{l}\text { OPE, } \\
\text { ICU }\end{array}$ & - \\
\hline & $\mathrm{NICO}$ & Partial $\mathrm{CO}_{2}$ & Less invasive than PCA systems & Not enough validation studies & OPE & - \\
\hline & & re-inhalation & & Artifacts with intrapulmonary shunt & & \\
\hline & Masimo & Plethysmography & Non-invasive monitoring & Impacted by the perfusion index & OPE & + \\
\hline & $\begin{array}{l}\text { Radical } \\
7\end{array}$ & & Allows PVI measurement & & & \\
\hline
\end{tabular}

$G D T$ goal-directed therapy, $\mathrm{CO}$ cardiac output, $\mathrm{SvO}_{2}$ mixed venous oxygen saturation, $O P E$ operating room, $I C U$ intensive care unit, $P C A$ pulse contour analysis, $\mathrm{ScvO}_{2}$ central venous oxygen saturation

techniques, esophageal Doppler, partial carbon dioxide rebreathing, and bioimpedance) did not achieve a percentage error of agreement with thermodilution of $\leq 30 \%$ suggested by Critchley and Critchley [32]. However, although important, the percentage error of agreement is only one marker of acceptability. In our opinion, the device capacity to track real time changes in $\mathrm{CO}$ may be more important than the ability of the monitor to deliver a highly accurate single measurement. This is especially true in hemodynamically unstable patients $[33,34]$ because it directly impacts the immediate clinical decision making and therapeutic interventions.

We will describe below the most common and relevant technologies used for GDT. Table 2 shows the list of all hemodynamic monitoring systems and describes their clinical potential.

\section{Pulmonary Artery Catheter}

The PAC obtains direct measurements of central venous, right-sided intracardiac, pulmonary arterial, and pulmonary artery wedge pressures. Moreover, it can estimate CO, systemic vascular resistance, and pulmonary vascular resistance. PAC is therefore considered to be the reference $\mathrm{CO}$ monitoring standard against which all new $\mathrm{CO}$ devices have been compared. Even though it is considered the current gold standard, its accuracy is between 12 and $15 \%$ for triplicate injection of iced saline and even worse under 
other specific conditions (elderly, obesity, less than three injections) $[35,36]$. Functionally, other patients conditions (mitral or tricuspid valve insufficiency, shunt) or misplacement of the PAC may influence reliable CO assessment [37].

Insertion of PAC is associated with an increased risk of various perioperative complications such as arrhythmia, air embolism, pneumothorax, and pulmonary artery rupture [38]. Also, some studies have suggested that the use of PAC for critically ill patients does not actually improve outcome [39-44]. Even with the current risk-to-reward ratio, this device can still occasionally be useful for critically ill patients with low $\mathrm{CO}$ undergoing cardiac surgeries and even more rarely in very sick cardiac patients undergoing non-cardiac surgery. As the PAC's dominance is dwindling in the ICU, its prospects in the OR are also threatened by the growing application of transesophageal echocardiography (TEE). The ASA guidelines currently suggest that the decision to utilize a PAC depends on a hazy combination of risks derived from the patient, the surgery, and the practice setting. Essentially, this decision should be made on a case-by-case basis.

\section{Pulse Contour Analysis}

Pulse contour analysis systems are based on the relationship between SV, peripheral vascular resistance, arterial pressure, and arterial compliance [45]. These systems measure $\mathrm{CO}$ indirectly from an arterial waveform analysis. Seven systems using different analysis algorithms are available, which are divided into 2 groups: (1) pulse contour analysis system, which needs a dilution $\mathrm{CO}$ measurement for calibration (PiCCO: Pulsion Medical Systems, Munish, Germany; Volume view: Edwards Lifesciences, Irvine, CA, USA; and LiDCO plus: LiDCO, London, UK), and (2) pulse contour analysis system requiring no calibration (LiDCO rapid: LiDCO, London, UK; Vigileo-FloTrac: Edwards Lifesciences, Irvine, CA, USA; PRAM: Vyetech Health, Padua, Italy; and Pulsioflex: Pulsion Medical Systems, Munish, Germany). The accuracy of the pulse pressure analysis method in estimating $\mathrm{CO}$ has been extensively investigated against $\mathrm{CO}$ calculations by thermodilution method using the PAC. One example is a recent meta-analysis [46] for the Flotrac/ Vigileo that showed improved correlation between this device and the thermodilution method when the new generation software was used as opposed to the initially poor correlation with previous generations. Once again, we must take into consideration that pulse pressure analysis may be of limited accuracy during periods of hemodynamic instability (i.e., rapid changes in vascular resistance) and this may especially be a problem for uncalibrated pulse pressure analysis. In contrast, although calibrated pulse pressure analysis may prove more accurate, they may also require frequent recalibration to maintain continued accuracy.

These systems are also able to measure dynamic indices of fluid responsiveness, including pulse pressure variation (PPV) and stroke volume variation (SVV). In the past decades, it has been shown that static indices such as CVP, PCWP, left ventricular end diastolic area, and right ventricular end-diastolic volume are not accurate for the prediction of fluid responsiveness [13, 47-51]. In contrast, several studies have shown that dynamic indices, such as SVV and PPV, are able to predict fluid responsiveness accurately [52-56]. However, dynamic indices based on cardiopulmonary interactions have several limitations. First, these variables should only be assessed in patients who are properly anesthetized on mechanical ventilation [57]. Moreover, tidal volume has an impact on the predictive reliability of SVV and PPV and the tidal volume must be at least $6 \mathrm{ml} / \mathrm{kg}$ to allow PPV or SVV to predict fluid responsiveness [58]. As expected, patients must be in sinus rhythm, closed-chest, and experiencing normal intraabdominal pressure [59]. Despite a strong predictive value, PPV results may fall within the inconclusive "gray zone" (between $9 \%$ and $13 \%$ ) in approximately $25 \%$ of patients during general anesthesia [52]. Both cardiovascular (rhythm, cardiac function, ventricular afterload, and heart rate) and respiratory issues (tidal volume, positive endexpiratory pressure, lung compliance, and chest compliance) need to be acknowledged. All of these limitations have to be considered before using dynamic indices in the OR or ICU settings.

\section{Non-invasive Monitoring}

\section{Ultrasound}

Briefly, the velocity of any moving object can be estimated by analyzing the frequency difference between the incident and reflected ultrasound waves. The Doppler equation defines this relationship more precisely with $(v)$ the velocity of the target, $(\theta)$ the incident angle, $(c)$ speed of sound in the medium, $(\Delta f)$ the frequency difference, and $\left(f_{0}\right)$ the frequency of the originally emitted ultrasound beam.

$v=\cos (\theta) c \Delta f / 2 f_{0}$

Clinically, the esophageal Doppler (CardioQ; Deltex Medical, Chichester, UK) provides hemodynamic data including SV, SVV, CO, and corrected flow time (FTc) by utilizing this equation to measure blood flow velocity in the descending aorta. The probe is placed in the esophagus and then rotated to the direction facing the descending aorta. $\mathrm{CO}$ is then calculated by measuring the flow velocity of 
blood. The diameter of the aorta is calculated based on the patient's demographics. FTc is inversely correlated with the systemic vascular resistance and, thus a common reason for short FTc $(<330 \mathrm{~ms})$ is hypovolemia. One concern for the use of esophageal Doppler (EDM) in CO measurement is determining if the ratio of blood entering the descending aorta from the left ventricle is constant. Previous studies have shown that in patients with unstable hemodynamic state, a disproportionate percentage of the $\mathrm{CO}$ increase following volume loading was directed to the carotid arteries [60]. Therefore, when conducting GDT based on esophageal Doppler in critically ill patients, one has to keep in mind that an increase in blood velocity in the descending aorta may not necessarily correlate with an increase in total SV [61]. However, to date, esophageal Doppler is the device with the most positive GDT studies in the perioperative setting.

The USCOM system (USCOM Ltd, Sydney, Australia) is also a noninvasive monitoring device using Doppler technology to measure stroke SV and its derived parameters. The probe of the USCOM system is positioned at the supraclavicular or suprasternal notch to measure blood flow of the left and right ventricular outflow tracts. This system is completely non-invasive and requires no calibration. However, it is observer-dependent and does not provide continuous information. Unfortunately, there are currently not enough validation studies employing this monitor. Thom et al. [62] reported poor agreement between CO measurements done with the USCOM system and PAC. On the other hand, Chand et al. [63] revealed good correlation in the same type of patients. Further studies are needed to fully validate this approach in various clinical settings.

\section{Plethysmography}

Pleth variability index (PVI) (Masimo Corp., Irvine, CA, USA) has been the most widely studied noninvasive monitoring system when looking specifically at GDT. PVI measures the minimal and maximal plethysmographic waveform amplitudes $(\triangle \mathrm{POP})$ during respiratory cycle and calculates the percentage difference. PVI has been shown to be a good predictor of fluid responsiveness in the OR and ICU [64, 65]. A recent meta-analysis [66] concluded that PVI had acceptable reliability in predicting fluid responsiveness in ventilated patients. However, changes in vasomotor tone, vasopressors administration, and other conditions such as hypothermia have a direct impact on the plethysmographic waveform and should be well known as its potential limitations $[67,68]$. Consequently, PVI should continue to be analyzed under stable and unstable conditions in order to more accurately determine the specific limitations.
Non-calibrated Pulse Contour Analysis

The Nexfin (Edwards Lifesciences, Irvine, CA) is a particularly novel non-invasive $\mathrm{CO}$ monitor among the various devices available today. This system estimates CO in two steps. First, this system includes cuffs to be wrapped around the patient's fingers that enable a continuous measurement of the arterial pressure curve based on the volume-clamp methodology [69]. This approach utilizes a photoplethysmographic device that measures the diameter of the arteries in the finger. A fast servo-controlled system inflates the cuff wrapped around the finger to maintain the arteries' diameter in the finger constant, which then allows the cuff pressures to estimate the arterial blood pressure. Second, the Nexfin device estimates CO based on a pulse contour analysis methodology described by Bogert et al. [70]. This device has been somewhat largely validated for $\mathrm{CO}$ monitoring and shows promise for future GDT trials $[69,71-73]$.

\section{Thoracic Electrical Bioimpedance}

This technique was founded on the concept that electrical conducting properties of the thoracic space vary with the amount of blood contained therein. Measurements of $\mathrm{CO}$ are made by measuring changes in determining flow $(I)$ and thoracic impedance $(Z)$ based on its relationship to electrical potential difference $(E)$ that are defined by Ohm's law:

$I=E / Z$

Recently, concerns have surfaced over the levels of accuracy of CO achieved with this technology and it has been shown a poor agreement between thoracic electrical bioimpedance and the reference method. [74-76]. Variance in electric skin conductivity between the body and the electrodes including temperature and humidity [77, 78], patient movement and lack of clinician attention to exact placement of sticker-electrodes and electric noise may contribute to inaccurate and variables measurements reading $[77,79,80]$.

\section{Bioreactance}

Because of the limitations of bioimpedance devices, bioreactance technology, which is newer method of processing the impedance signal, has been developed and is based on the discovery that changes in aortic blood volume induce small changes in the frequency of electrical signals propagating across the thorax. The NICOM system (Cheetah Medical, Portland, OR) uses an algorithm which measures phase shifts in high-frequency waves transmitted across the thorax, with a nearly 100 -fold improvement in the signal- 
to-noise ratio and thus in an improved performance of this technology. This device consists of four pads placed across the thorax which are connected to a monitor [81]. CO assessment by the NICOM system can be achieved in nonventilated and ventilated patients alike, and can be computed in patients with cardiac arrhythmias. The NICOM system has been validated with clinically acceptable reliability when compared with PAC in critically ill patients $[82,83]$. A recently published study using the bioreactance technology as a GDT monitor has been shown to perform similarly to the Esophageal Doppler method [81].

\section{Partial $\mathrm{CO}_{2}$ Re-inhalation}

$\mathrm{CO}$ can be calculated by the $\mathrm{CO}_{2}$ partial rebreathing technique using the modified Fick equation [84]. The NICO device (Novametrix Medical Systems, Wallingford, USA) measures $\mathrm{CO}$ on this principle. This system has some limitations including, but not limited to, false $\mathrm{CO}_{2}$ changes obtained both in ventilation and dead space. There are currently few validation studies of this system. Kotake et al. [85] demonstrated a poor agreement of this system in $\mathrm{CO}$ measurement against PAC in cardiac surgical patients. Overall, this system is presently not interchangeable for PAC, but constitutes a feasible alternative in critically ill patients in the future if reasonable evidence emerges.

\section{Additional Hemodynamic Variables}

$\mathrm{ScvO}_{2}$

Monitoring of mixed venous oxygen saturation $\left(\mathrm{SvO}_{2}\right)$ has been used as a simple method for evaluating changes in the systemic oxygen supply to demand ratio in various clinical settings [39, 41]. Unfortunately, a PAC is currently required to obtain $\mathrm{SvO}_{2}$. Fortunately, $\mathrm{ScvO}_{2}$ may represent an attractive alternative because it can more easily be measured using a central venous catheter. Reinhart et al. have shown that $\mathrm{ScvO}_{2}$ has a good correlation with $\mathrm{SvO}_{2}$ [86]. However, there is still debate regarding the equivalence between these two values [87-90] especially when they are low [91]. The surviving Sepsis Campaign recognized the clinical importance of $\mathrm{ScvO}_{2}$ and recommended to keep $\mathrm{ScvO}_{2}$ more than $70 \%$ during the resuscitation of septic shock patients. A multi-center study to assess the incidence of low $\mathrm{ScvO}_{2}$ in high-risk surgical patients revealed that the low $\mathrm{ScvO}_{2}$ correlated with an increased risk of postoperative complications in high-risk surgical patients [92]. They also determined that the best cut-off value for $\mathrm{ScvO}_{2}$ in predicting postoperative complications was $73 \%$ [92]. However, more recently, the multicenter, randomized protocolized care for early septic shock
(ProCESS) trial was conducted at 31 hospitals in the United States and revealed that protocol-based GDT including the use of $\mathrm{ScvO}_{2}$ did not improve the outcomes in septic patients [93*0]. As CVP access is common in high risk patients, there is still much room for growth in using $\mathrm{ScvO}_{2}$ for GDT in this patient population. Hopefully future research protocols will address such a knowledge gap.

\section{Veno-arterial Carbon Dioxide Gradient $\left(\mathrm{P}(\mathrm{v}-\mathrm{a}) \mathrm{CO}_{2}\right)$}

The central venous to arterial carbon dioxide difference $\mathrm{P}(\mathrm{v}-\mathrm{a}) \mathrm{CO}_{2}$ has been proposed by some authors for assessment of tissue perfusion [94, 95]. Values of $\mathrm{P}(\mathrm{v}-\mathrm{a}) \mathrm{CO}_{2}$ larger than $6 \mathrm{mmHg}$ were found to be associated with poor outcome and organ dysfunctions [94, 96]. Additional research on the defined clinical practicality of this variable is pending.

\section{Cerebral Oximetry}

Cerebral oximetry estimates the oxygenation of regional tissue by transcutaneous measurement of the frontal cerebral cortex, which is an area of the brain that is particularly susceptible to hypoxia [97]. In fact, the brain receives around $20 \%$ of the $\mathrm{CO}$ and, concordantly, consumes approximately $20 \%$ of the total body oxygen. Therefore, cerebral oximetry has gained increasing popularity as a monitor capable of detecting cerebral ischemia.

Beyond providing continuous insight into regional oxygenation of the brain, cerebral oximetry may provide additional utility for patient care. For instance, it may allow clinicians to use the brain as an index organ that represents the adequacy of tissue perfusion and oxygenation of other vital organs. Also, there is increasing interest in the utilization of similar oximetry sensors to monitor adequacy of tissue perfusion when placed on non-cerebral anatomic sites in both adult and pediatric patients [98, 99].

Significant falls in $\mathrm{rSO}_{2}$ have been shown to predict poor outcomes (cerebral and non-cerebral) in cardiac and non-cardiac surgical patients [100-102]. The most important approach is to maintain $\mathrm{rSO}_{2}$ within $20 \%$ of baseline in these patient groups in order to reduce postoperative complications [101, 103]. This monitoring device is an early warning system for picking up imbalances between cerebral oxygen supply and demand, especially deficient cerebral oxygen delivery, and acts as an indicator of cerebral ischemia. The maintenance of an adequate cerebral oxygenation helps to ensure intraoperative optimization of oxygen delivery and may improve outcomes [104]. It seems to be a promising technology but has not been formally evaluated in a formalized GDT protocol. 


\section{How to Apply GDT in the Operating Room}

In this chapter, we will discuss how some of the devices described in the previous section have been used in the OR alongside standardized protocols and how this implementation has impacted patient outcome. Table 3 shows the most famous GDT protocols in the OR in patients undergoing major surgery.

It is well known that patients with stronger preoperative risk factors are less likely to survive the procedure and more likely to develop post-surgical complications. As such, GDT in high risk surgical patients is likely to have the greatest benefit if carried out early with a predefined protocol. In a recent meta-analysis investigating the effect of GDT on different risk groups [105••], the mortality benefit of GDT was limited to the extremely high-risk group patients [odds ratio $(\mathrm{OR})=0.27,95 \%$ confidence interval (CI) $0.15-0.51, p<0.00001$ ). Complication rates were reduced in all risk subgroups $(\mathrm{OR}=0.45,95 \% \mathrm{CI}$ $0.34-0.60, \mathrm{p}<0.00001)$. Pearse et al. [26••] conducted a randomized clinical trial in 734 high-risk patients undergoing major gastrointestinal surgery, and revealed that GDT using CO-guided hemodynamic management did not provide significant decreases in 30-day major complications and mortality (relative risk $=0.84,95 \%$ CI 0.71-1.01). However, in a meta-analysis of 38 trials including this data, they also indicated that the hemodynamic intervention was related to a reduction in postoperative complications (intervention $31.5 \%$, control $41.6 \%$; relative risk $=0.77,95 \%$ CI $0.71-0.83$ ). It should be mentioned that one must remember to consider publication bias in such a study as negative results are much more difficult to publish and less pursued by investigators when compared to positive results.

The first step for proper GDT implementation in the OR is to identify the patient's surgical risk and to determine appropriate vascular access. Once established, one can choose the best available monitoring approach and the suitable hemodynamic optimization protocol. Figure 2 lists appropriate suggestions for the choice of the hemodynamic monitoring system based on a patient's risk factors and vascular access. The main message to keep in mind is that choosing the most appropriate hemodynamic monitor is "context dependent" ("no high heels on the farm, no clogs to the opera") [106]. During high risk surgery, invasive or minimally invasive monitoring devices (more robust signals, better accuracy) are more suitable in hemodynamically unstable patients or when postoperative complications are likely to occur (best therapeutic decision making). In other lower risk cases, the risks associated with an invasive monitor outweigh its expected benefits. For these situations, clinicians may choose accept the lower accuracy provided by noninvasive $\mathrm{CO}$ monitoring devices because there is no justification in using invasive arterial lines in patients who are at lower risks just because the device is more accurate.

\section{Protocol for Low Risk Surgery}

Low risk surgery is defined as meeting all of the following criteria: (1) patient is classified as American Society Anesthesiologist (ASA) physical status 1 or 2, (2) the surgery has expected blood loss less than $500 \mathrm{ml}$, and (3) the surgical case is either gynecologic, breast, ophthalmologic, stomatologic, endocrinology (except pheochromocytoma and carcinoid tumor), minor urologic, plastic, or minor orthopedic. In a recent simulation study of GDT, it was shown that GDT is cost-effective and associated with cost savings [107]. Therefore, in low risk patients, it is recommended to use peripheral intravenous access and, in addition to the standard monitors, employ a non-invasive hemodynamic monitor for GDT such as PVI. Figure 3 shows an example protocol for GDT using PVI. The goal for GDT in this example is to use a baseline crystalloid administration of 3 to $5 \mathrm{ml} / \mathrm{kg} / \mathrm{h}$ and then to titrate volume expansion using PVI. Forget et al. [108] conducted a randomized controlled trial (RCT) to investigate the impact of GDT using PVI in patients scheduled for major abdominal surgery. The PVI group patients were administered colloids of $250 \mathrm{~mL}$ if the PVI was over $13 \%$. As the result, intraoperative infusion volume was significantly lower in the PVI group. Lactate levels were significantly lower in the PVI group during surgery and $48 \mathrm{~h}$ after surgery $(p<0.05)$.

\section{Protocol for Moderate Risk Surgery}

Moderate risk surgery is defined as follows: (1) patient is classified as ASA physical status 2 or 3,(2) the expected blood loss is less than $1500 \mathrm{ml}$, and (3) the surgery type is either abdominal, head and neck, major orthopedic surgery, peripheral angiography, kidney transplantation, or urologic. For these moderate risk surgical patients, one can use one or two peripheral intravenous lines and/or an arterial line.

- In patients without an arterial line, the "NICE protocol" released in March 2011 by the NHS in the UK [109] can be applied (Fig. 4). The goal is to titrate fluid loading in order to maximize SV. Also, the GDT protocol suggested by Gan et al. [16] can be used (Fig. 5). They reported lower incidence of postoperative nausea and vomiting, earlier return to bowel function, and decrease in length of postoperative hospital stay using the esophageal doppler to maximize SV. 
Table 3 Goal-directed therapy in the operating room in patients undergoing major surgery

\begin{tabular}{|c|c|c|c|c|c|}
\hline Author & $\begin{array}{l}\text { Surgical } \\
\text { type }\end{array}$ & Patient & Monitor & $\begin{array}{l}\text { Guiding } \\
\text { goals }\end{array}$ & Results \\
\hline Gan [16] & Abdominal & 100 & ED & SV, FTc & $\downarrow$ Hospital LOS and PONV \\
\hline Forget [108] & Abdominal & 82 & Pulse oximeter & PVI & $\begin{array}{l}\downarrow \text { Infusion volume } \\
\downarrow \text { Intraoperative lactate levels }\end{array}$ \\
\hline Benes [130] & Abdominal & 120 & VF & SVV & $\downarrow$ Complications and hospital LOS \\
\hline Mayer [19] & Abdominal & 60 & VF & SVV & $\begin{array}{l}\downarrow \text { Complications and hospital LOS } \\
\text { No difference in ICU LOS }\end{array}$ \\
\hline $\begin{array}{l}\text { Ramsingh } \\
{[110]}\end{array}$ & Abdominal & 38 & VF & SVV & $\begin{array}{l}\text { Faster return of GI function } \\
\downarrow \text { Hospital LOS }\end{array}$ \\
\hline Schereen [131] & Abdominal & 64 & VF & SVV & $\downarrow$ Infections in surgical sites \\
\hline Zheng [132] & Abdominal & 60 & $\mathrm{VF}$ & SVV & $\begin{array}{l}\text { Faster return of GI function } \\
\downarrow \text { Hospital LOS and ICU LOS }\end{array}$ \\
\hline Lopes [133] & Abdominal & 33 & $\begin{array}{l}\text { Standard } \\
\text { monitoring }\end{array}$ & PPV & $\begin{array}{l}\downarrow \text { Complications } \\
\downarrow \text { Hospital LOS and ICU LOS } \\
\downarrow \text { Time of mechanical ventilation }\end{array}$ \\
\hline $\begin{array}{l}\text { Salzwedel } \\
{[134]}\end{array}$ & Abdominal & 160 & ProAQT & PPV & $\begin{array}{l}\downarrow \text { Complications } \\
\text { No difference in ICU LOS }\end{array}$ \\
\hline $\begin{array}{l}\text { Wackeling } \\
{[18]}\end{array}$ & Abdominal & 128 & ED & SV, CVP & $\begin{array}{l}\uparrow \text { Gut function recovery } \\
\downarrow \text { GI complications and hospital LOS }\end{array}$ \\
\hline Conway [135] & Abdominal & 55 & $\mathrm{ED}$ & FTc, SV & $\downarrow$ ICU LOS \\
\hline Buettner [136] & Abdominal & 80 & $\mathrm{PiCCO}$ & SPV & $\begin{array}{l}\text { No difference in ICU LOS, hospital LOS, morbidity and } \\
\text { mortality }\end{array}$ \\
\hline Donati [119] & Abdominal & 135 & $\mathrm{ScvO}_{2}$ & $\mathrm{ERO}_{2}$ & $\begin{array}{l}\downarrow \text { Postoperative organ failure } \\
\downarrow \text { Hospital LOS }\end{array}$ \\
\hline
\end{tabular}

$V F$ vigileo-FloTrac system, $E D$ esophageal Doppler, $S c v O_{2}$ central venous oxygen saturation, $S V$ stroke volume, $F T c$ corrected flow time, $P V I$ pleth variability index, $S V V$ stroke volume variation, $P P V$ pulse pressure variation, $C V P$ central venous pressure, $E R O_{2}$ oxygen extraction, $L O S$ length of stay, $P O N V$ postoperative nausea and vomiting, $I C U$ intensive care unit, $G I$ gastrointestinal

- In patients with arterial lines, CO monitoring based on arterial pressure waveform can be applied for GDT protocol. Figure 6 demonstrates an example of a GDT algorithm using SVV and PPV in the OR that can be applied this situation. When employing SVV or PPV for GDT, the patient should be intubated with general anesthesia, have a sinus rhythm, and have a tidal volume $>8 \mathrm{~mL} / \mathrm{kg}$. Ramsingh et al. [110] conducted a GDT protocol (Fig. 7) to maintain SVV $<12 \%$ using the Vigileo-FloTrac system in low to moderate risk patients undergoing high risk abdominal surgery. They reported that the GDT group patients had faster return of gastrointestinal function $(p=0.004)$ and higher "quality of recovery" scores.

\section{Protocol for High Risk Surgery}

Upgrading surgical patients from moderate risk to high risk is dependent on surgical criteria, patient-related factors and/ or formal dynamic testing of functional capacity. High risk surgical patients are those with an individual mortality risk greater than $5 \%$ or undergoing a surgery carrying a $5 \%$ mortality. These patients commonly have a limited physiological cardiopulmonary reserve and an inability to meet the increased oxygen demand imposed by the perioperative surgical stress during major surgery which is associated with a significant mortality risk. In addition to these patient specific risk factors, perioperative risk factors include multiple interventions that can negatively influence the balance between oxygen demand and consumption. Nociceptive surgical stimulations, volume variations due to acute blood losses or transfusions and administration of anesthetic agent can significantly influence this $\mathrm{VO}_{2}-\mathrm{DO}_{2}$ relationship. Some studies evaluated the $\mathrm{VO}_{2}-\mathrm{DO}_{2}$ relationship in major surgery [111-113] and showed a decreased capacity for tissue $\mathrm{O}_{2}$ extraction which may have lead to tissue hypoxia [114]. These observations demonstrate the importance of adequately evaluating the $\mathrm{DO}_{2}-\mathrm{VO}_{2}$ relationship in conjunction with the patient's metabolic demand, which is once again strongly affected by surgical conditions.

Initially, significant perioperative cardiopulmonary optimization information came from observational data 
published by Shoemaker 30 years ago [115]. He recognized that, during the perioperative period, patient developed an "oxygen debt" (imbalance between global oxygen delivery and oxygen consumption). If their cardiopulmonary reserve was limited, they were less likely to meet the increased oxygen demand incurred during major surgery [116]. He used predefined hemodynamic measures (oxygen delivery index) to guide therapy and observed that patients who survived from major surgery had higher $\mathrm{DO}_{2}$ values than non survivors. Using these data, an early GDT aimed at supra optimizing postoperative $\mathrm{DO}_{2}$ resulted in lowered complications, LOS, mechanical ventilation, and overall cost. The patients who experienced postoperative complications tended to be those that could also not increase their $\mathrm{CO}$ to meet the increased demand of surgery. However, this approach is not beneficial to every high risk surgical patient because their level of oxygen demand, degree of cardiac function alteration, and capacities of oxygen extraction may significantly vary. Thus, the major concern of the anesthetist in the perioperative period is to optimize the patient's individual volemic status by aiming to achieve well-defined goals (based on flow related parameters such as stroke volume) in order to maximize end organ oxygen delivery.

$\mathrm{SvO}_{2}$ can give information about tissue oxygen consumption and can be collected in conjunction with $\mathrm{CO}$ and multiple other cardiopulmonary variables during PAC catheterization. Lobo et al. [117] conducted a RCT to investigate the impact of GDT (using PAC) on postoperative outcomes in high-risk surgical patients undergoing major abdominal surgery. The GDT group was managed with the goal of supranormal values (oxygen delivery index $>600 \mathrm{~mL} / \mathrm{min}^{2}$ ). They reported a decrease in cardiovascular complications and 60-day mortality rates in the GDT group. Unfortunately, $\mathrm{SvO}_{2}$ and other cardiopulmonary variables require a PAC insertion, which comes with inherent risks only rarely clinically justifiable [118]. As mentioned above, collecting $\mathrm{ScvO}_{2}$ for use as a GDT endpoint is more easily accessible through a central venous catheter. Donati et al. [119] revealed improved outcomes in GDT group patients using dobutamine and fluids titrated to optimize oxygen extraction less than $27 \%\left(\mathrm{ScvO}_{2}>73 \%\right)$. Additionally, a decreased $\mathrm{ScvO}_{2}$ in the perioperative period is independently correlated with increased postoperative complications [120]. Regardless, there is still room for further $\mathrm{ScvO}_{2}$ clinical research, especially as it pertains to high surgical risk GDT. Figure 8 shows an example protocol using $\mathrm{ScvO}_{2}$ adapted from the report by Vallet et al. [121].

Once again, as with any emergent technology, GDT is meant to be used as one piece of a much larger puzzle and should be interpreted within the wider clinical context in an individualized approach.
Future Perspectives: Closed-Loop Fluid Administration System

What is the next step for GDT? As this evidence-based approach to fluid management becomes more consistently accepted among leading institutions around the world, we believe the next step is closing the automation loop between data collection and fluid management interventions. It is best to think of this closed loop as powerful but easily broken if the physician anesthesiologist encounters a clinical situation where standardization may not be the best approach. At UC Irvine Medical Center (Orange, CA, USA), we have recently described a novel-closed loop fluid administration system based on SV monitoring and optimization (Learning Intravenous Resuscitator ${ }^{\odot}$ ) $[122,123]$. The aim of this system is to ease implementation of protocols in clinical settings and to apply goal-directed fluid therapy automatically. After conducting simulation [122, 123], engineering [124], and animal studies [125], it is now starting to be used in the OR with semi-invasive [126] and, more recently, non-invasive devices.

This system is designed to titrate the fluid administration rate until stroke volume reaches the plateau of the Frankstarling relationship. Once accomplished, the next step is to then maintain the patient's volume status on that plateau throughout the surgical intervention. To achieve this goal, the closed-loop system monitors SV, tracks volume expansion-induced changes in SV and uses PPV or SVV to refine fluid responsiveness predictions [30, 52]. The benefits seem already obvious: targeting a parameter with greater accuracy, decreasing the hemodynamic variability, reducing inattention and human error, and allowing the clinician to concentrate on other tasks. This system is certainly not designed to replace the physician anesthesiologist, just as aviation closed-loop systems (e.g. autopilot) are not designed to replace the pilot. Similarly, this new technology should increase safety by reducing variability and improving patient outcome. It is important to note that future clinical studies are indicated to confirm the real benefit of this system in the anesthesia setting even if the primary results of current clinical trials have shown that the overall strategy is feasible and encouraging.

\section{Conclusions}

The importance of goal-directed perioperativehemodynamic optimization has increased in the past decade and has evolved alongside hemodynamic monitoring technology. As a result, endpoints used for this optimization have also advanced, with a shift from more static to more dynamic variables. Using such goal-directed therapies, there is growing evidence in moderate to high risk surgical 


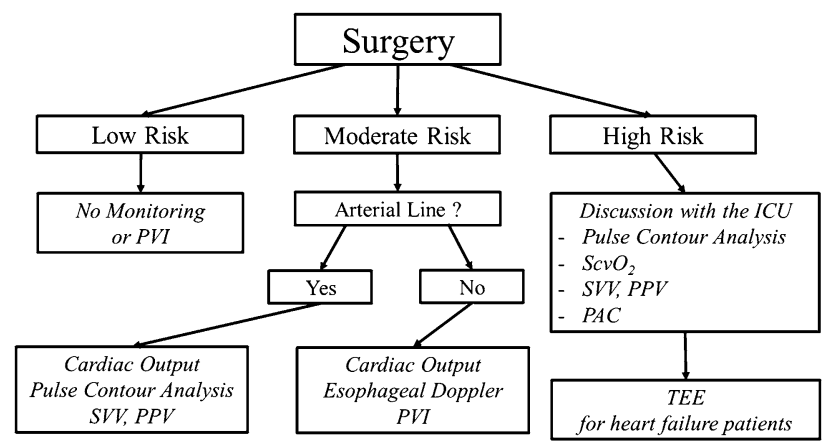

Fig. $2 P V I$ pleth variability index, $S V V$ stroke volume variation, $P P V$ pulse pressure variation, $I C U$ intensive care unit, $\mathrm{ScvO}_{2}$ central venous oxygen saturation, $P A C$ pulmonary artery catheter, TEE transesophageal echocardiography. A suggestion for the choice of the hemodynamic monitoring systembased on patient's risk and vascular access. The first step for goal-directed therapy in the operating room is to identify the risk of surgical patients and then to decide the vascular access

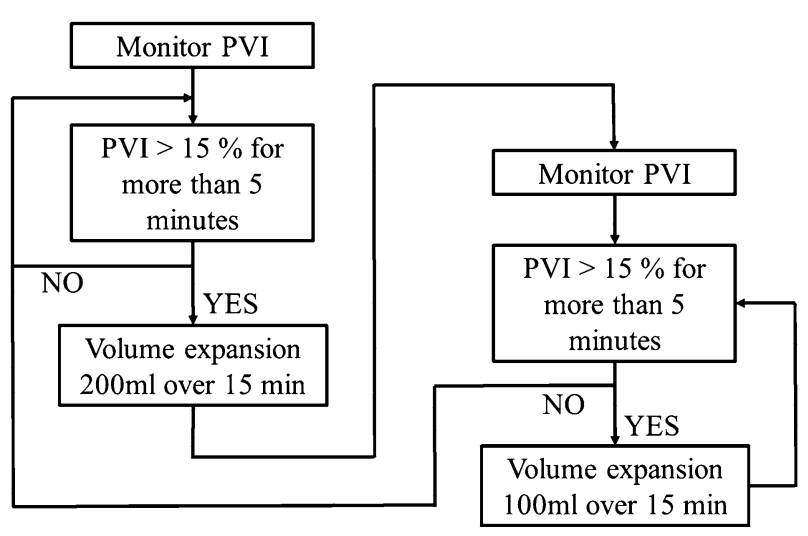

Fig. 3 PVI pleth variability index. The example protocol for goaldirected therapy using PVI. The goal for goal-directed therapy is to use a baseline crystalloid administration and to titrate volume expansion based on PVI. In this protocol, the goal for PVI is to be less than $15 \%$

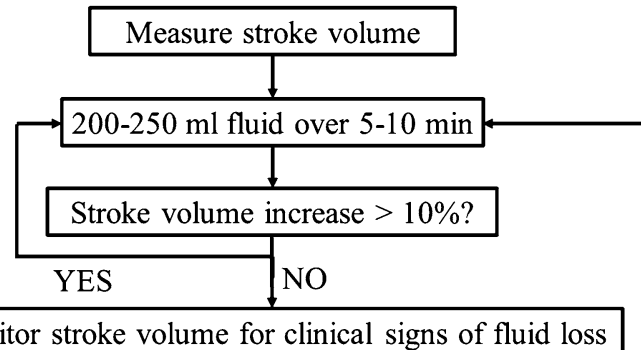

Monitor stroke volume for clinical signs of fluid loss

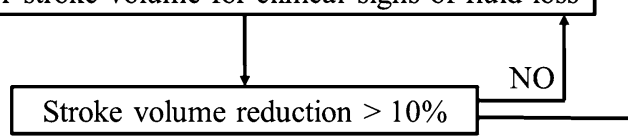

Fig. 4 NICE protocol by the National Health Service in the UK. The goal of this protocol is to titrate fluid loading in order to maximize stroke volume

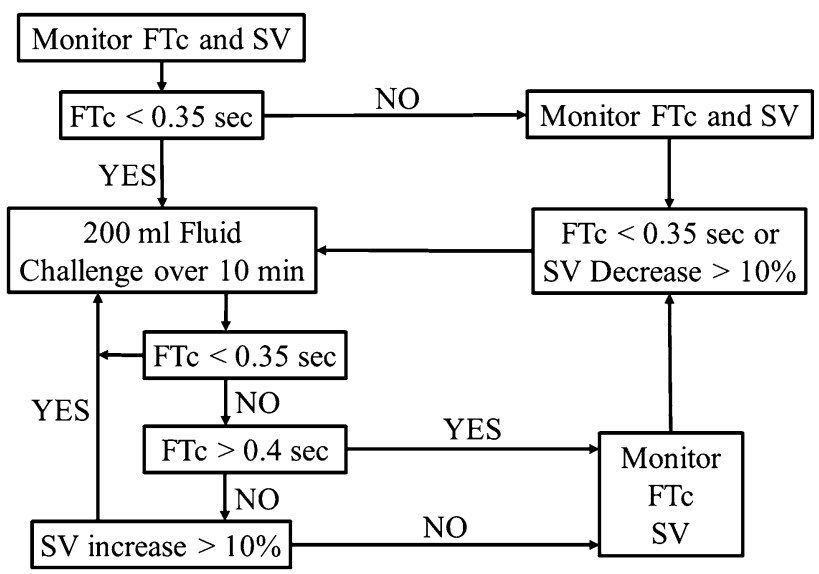

Fig. $5 F T C$ corrected flow time, $S V$ stroke volume. The goal-directed therapy protocol suggested by Gan et al. This protocol uses the indices of esophageal Doppler (FTc and SV) to maximize stroke volume

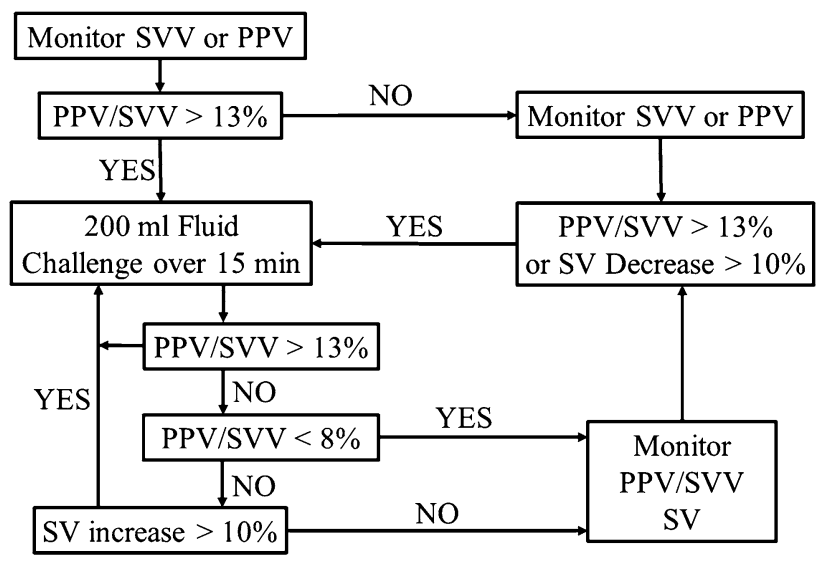

Fig. $6 S V V$ stroke volume variation, $P P V$ pulse pressure variation. The example protocol for goal-directed therapy using the SVV or PPV. The goal for goal-directed therapy is to titrate volume expansion based on SVV or PPV. In this protocol, the goal for SVV or PPV is less than $13 \%$

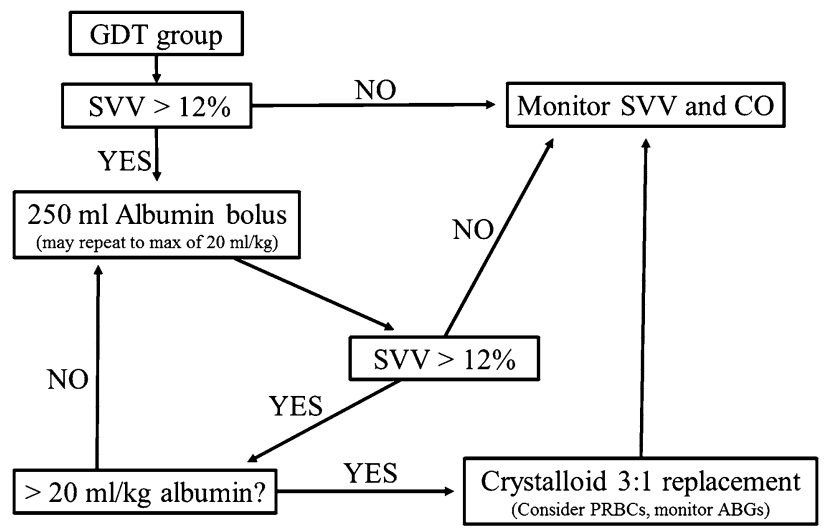

Fig. $7 S V V$ stroke volume variation, $C O$ cardiac output. The protocol for goal-directed therapy suggested by Ramsingh et al. This protocol uses the indices of Vigileo-FloTrac system (SVV and $\mathrm{CO}$ ) to maximize $\mathrm{CO}$ 
Fig. $8 \mathrm{ScvO}_{2}$ central venous oxygen saturation, $\mathrm{SaO}_{2}$ arterial oxygen saturation, PEEP positive end expiratory pressure, $A B G$ arterial blood gas, $H b$ Hemoglobin, $S V V$ stroke volume variation. The example protocol using $\mathrm{ScvO}_{2}$ adapted from the report by Vallet et al. In this protocol, the goal for $\mathrm{ScvO}_{2}$ is to be maintained above $75 \%$

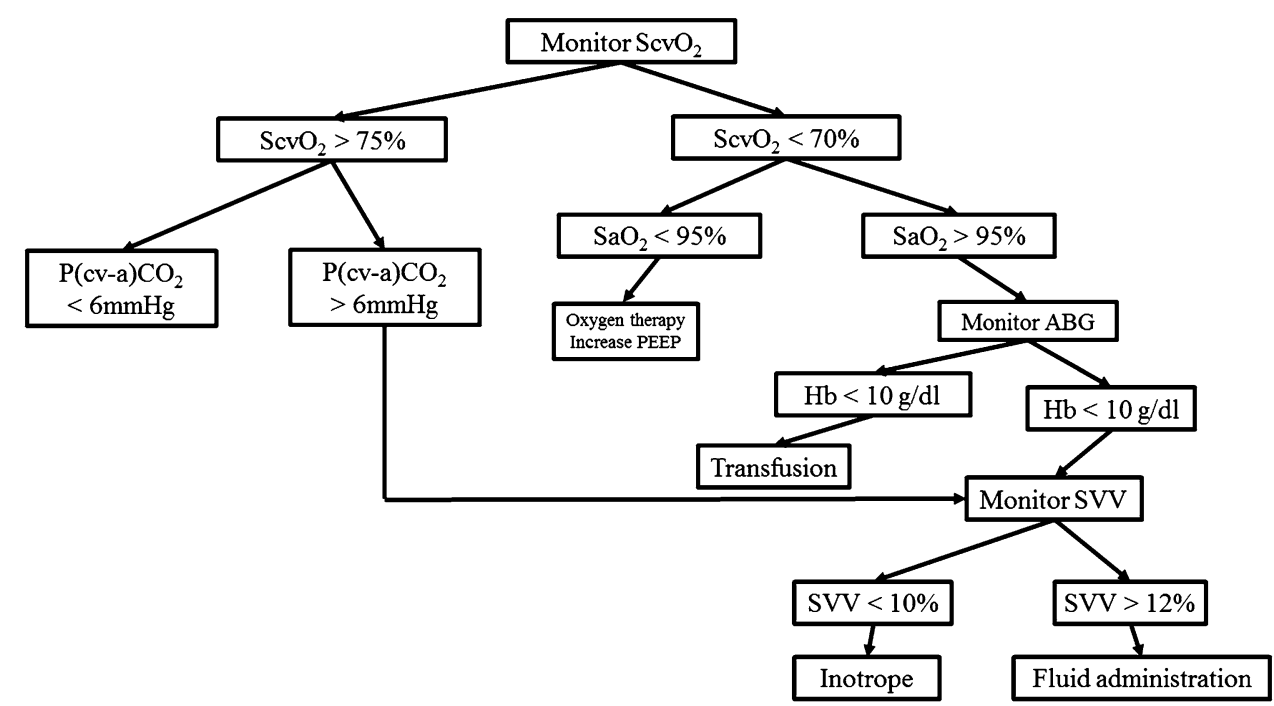

patients that appropriate treatment algorithms can improve outcomes especially if carried out early and in an individualized manner. As such, the increasing age and comorbidities of the surgical population clearly justify the use of advanced monitoring devices during the perioperative period. Nevertheless, some considerations need to be taken into account in the preoperative period when deciding to implement such devices in order to choose the right monitoring technology in the perioperative period (types of patient and surgery presence of an arterial line, exact knowledge of the device as well as its inherent limitations).

Despite all the evidence demonstrating the benefit of GDT, there is still no clear consensus about the most effective goals and the most appropriate monitoring device for guiding therapy. In fact, many endpoints and $\mathrm{CO}$ monitoring systems have been tested, both invasive and noninvasive, all with their own advantages and disadvantages. This has led to confusion in clinical practice about which device to use and within what specific algorithm. It is important to note that there are still only limited data showing that any of these specific monitoring devices will improve patient's outcome. Concordantly, the physician is held responsible for the correct understanding and interpretation of the available technologic and clinical data. One must then individualize and integrate such data into a full clinical picture of the patient in order to determine the best intervention.

Further creation, development and implementation of institutional perioperative GDT protocols and guidelines specific to the patients' status and type of surgery are necessary to minimize variability between clinicians and thus improve hemodynamic stability, optimize tissue perfusion, and decrease postoperative complications. Hopefully, these needs have begun to be considered by clinicians and departments in the wake of the recently developed ERAS program, PSH model, and the automatic closed-loop fluid administration system.

Acknowledgments This article was reviewed by Dr. Deepak K. Tempe of G.B. Pant Hospital at the University of New Delhi.

\section{Compliance with Ethics Guidelines}

Conflict of Interest Koichi Suehiro declares that he has no conflict of interest. Alexandre Joosten declares that he has no conflict of interest. Brenton Alexander declares that he has no conflict of interest. Maxime Cannesson has received financial support through grants from The University of California's Center for Health Quality and Innovation (CHQI), Edwards Lifesciences, and Masimo; has served as a board member for Gauss Surgical, Inc. and Sironis; has received compensation from Edwards Lifesciences, Masimo, Covidien, Draeger, and Philips for service as a consultant; and has received reimbursement for travel/accommodations expenses from Masimo.

Human and Animal Rights and Informed Consent This article does not contain any studies with human or animal subjects performed by any of the authors.

\section{References}

Papers of particular interest, published recently, have been highlighted as:

- Of importance

- Of major importance

1. Weiser TG, Regenbogen SE, Thompson KD, Haynes AB, Lipsitz SR, Berry WR, et al. An estimation of the global volume of surgery: a modelling strategy based on available data. Lancet. 2008;372:139-44.

2. Pearse RM, Harrison DA, James P, Watson D, Hinds C, Rhodes $\mathrm{A}$, et al. Identification and characterisation of the high-risk surgical population in the United Kingdom. Crit Care. 2006;10:R81. 
3. Bennett-Guerrero E, Welsby I, Dunn TJ, Young LR, Wahl TA, Diers TL, et al. The use of a postoperative morbidity survey to evaluate patients with prolonged hospitalization after routine, moderate-risk, elective surgery. Anesth Analg. 1999;89:514-9.

4. Pearse RM, Moreno RP, Bauer P, Pelosi P, Metnitz P, Spies C, et al. Mortality after surgery in Europe: a 7 day cohort study. Lancet. 2012;380:1059-65.

5. Gan TJ, Mythen MG. Does peroperative gut-mucosa hypoperfusion cause postoperative nausea and vomiting? Lancet. 1995;345:1123-4.

6. Guyton AH, Hall JE. Heart muscle; the heart as a pump and function of the heart valves. In: Elsevier S, editor. Textbook of medical physiology. 11th ed. Philadelphia: Elsevier Inc; 2006. p. $103-15$.

7. Guyton AH, Hall JE. Overview of the circulation: medical physics of pressure, flow, and resistance. In: Elsevier S, editor. Textbook of medical physiology. 11th ed. Philadelphia: Elsevier Inc; 2006. p. 161-70.

8. American Society of Anesthesiologists, Standards of the American Society of Anesthesiologists: Standards for Basic Anesthetic Monitoring. http://www.asahq.org/For-Members/ / media/For\%20Members/documents/Standards $\% 20$ Guidelines $\%$ 20Stmts/Basic\%20Anesthetic\%20Monitoring\%202011.ashx. Accessed 12 Jan 2012.

9. Cannesson M, Pestel G, Ricks C, Hoeft A, Perel A. Hemodynamic monitoring and management in patients undergoing high risk surgery: a survey among North American and European anesthesiologists. Crit Care. 2011;15:R197.

10. Cannesson M, Slieker J, Desebbe O, Bauer C, Chiari P, Henaine $\mathrm{R}$, et al. The ability of a novel algorithm for automatic estimation of the respiratory variations in arterial pulse pressure to monitor fluid responsiveness in the operating room. Anesth Analg. 2008;106:1195-200.

11. Michard F, Boussat S, Chemla D, Anguel N, Mercat A, Lecarpentier $\mathrm{Y}$, et al. Relation between respiratory changes in arterial pulse pressure and fluid responsiveness in septic patients with acute circulatory failure. Am J Respir Crit Care Med. 2000;162:134-8.

12. Cannesson M. Arterial pressure variation and goal-directed fluid therapy. J Cardiothorac Vasc Anesth. 2010;24:487-97.

13. Michard F. Changes in arterial pressure during mechanical ventilation. Anesthesiology. 2005;103:419-28.

14. Lansdorp B, Ouweneel D, de Keijzer A, van der Hoeven JG, Lemson J, Pickkers P. Non-invasive measurement of pulse pressure variation and systolic pressure variation using a finger cuff corresponds with intra-arterial measurement. $\mathrm{Br} \mathrm{J}$ Anaesth. 2011;107:540-5.

15. Pinsky MR, Payen D. Functional hemodynamic monitoring. Crit Care. 2005;9:566-72.

16. Gan TJ, Soppitt A, Maroof M, el-Moalem H, Robertson KM, Moretti E, et al. Goal-directed intraoperative fluid administration reduces length of hospital stay after major surgery. Anesthesiology. 2002;97:820-6.

17. Pearse R, Dawson D, Fawcett J, Rhodes A, Grounds RM, Bennet ED. Early goal-directed therapy after major surgery reduces complications and duration of hospital stay. A randomised, controlled trial [ISRCTN38797445]. Crit Care. 2005;9:R687-93.

18. Wakeling HG, McFall MR, Jenkins CS, Woods WG, Miles WF, Barclay GR, et al. Intraoperative oesophageal Doppler guided fluid management shortens postoperative hospital stay after major bowel surgery. Br J Anaesth. 2005;95:634-42.

19. Mayer J, Boldt J, Mengistu AM, Rohm KD, Suttner S. Goaldirected intraoperative therapy based on autocalibrated arterial pressure waveform analysis reduces hospital stay in high-risk surgical patients: a randomized, controlled trial. Crit Care. 2010;14:R18.

20. NICE draft guidance on cardiac output monitoring device published for consultation. 2011. http://www.nice.org.uk/newsroom/ pressreleases/DraftGuidanceOnCardiacOutputMonitoringDevice. jsp. Accessed 13 Feb 2014.

21. European Society of Anaesthesiology-Perioperative goaldirected therapy protocol summary. 2013. http://html.esahq.org/ patientsafetykit/resources/downloads/05_Checklists/Various_ Checklists/Perioperative_Goal_Directed_Therapy_Protocols. pdf. Accessed 13 Feb 2014.

22. Vallet B, Blanloeil Y, Cholley B, Orliaguet G, Pierre S, Tavernier B. Guidelines for perioperative haemodynamic optimization. Ann Fr Anesth Reanim. 2013;32:e151-8.

23. Miller TE, Roche AM, Gan TJ. Poor adoption of hemodynamic optimization during major surgery: are we practicing substandard care? Anesth Analg. 2011;112:1274-6.

24. Challand C, Struthers R, Sneyd JR, Erasmus PD, Mellor N, Hosie KB, et al. Randomized controlled trial of intraoperative goal-directed fluid therapy in aerobically fit and unfit patients having major colorectal surgery. Br J Anaesth. 2012;108:53-62.

25. Corcoran T, Rhodes JE, Clarke S, Myles PS, Ho KM. Perioperative fluid management strategies in major surgery: a stratified meta-analysis. Anesth Analg. 2012;114:640-51.

26. •- Pearse RM, Harrison DA, MacDonald N, Gillies MA, Blunt M, Ackland G et al. Effect of a perioperative, cardiac outputguided hemodynamic therapy algorithm on outcomes following major gastrointestinal surgery: a randomized clinical trial and systematic review. JAMA. 2014;311:2181-90. Pearse et al. conducted a randomized clinical trial in 734 high-risk patients undergoing major gastrointestinal surgery, and revealed that GDT using CO-guided hemodynamic management did not provide significant decreases in 30-day major complications and mortality (relative risk $=0.84,95 \%$ confidence interval 0.71 to 1.01). However, in a meta-analysis of 38 trials including this data, they also indicated that the hemodynamic intervention was related to a reduction in postoperative complications (intervention $31.5 \%$, control 41.6\%; relative risk $=0.77,95 \%$ confidence interval 0.71 to 0.83 ).

27. Gustafsson UO, Scott MJ, Schwenk W, Demartines N, Roulin D, Francis N, et al. Guidelines for perioperative care in elective colonic surgery: enhanced Recovery After Surgery (ERAS((R))) Society recommendations. World J Surg. 2013;37:259-84.

28. Kain ZN, Vakharia S, Garson L, Engwall S, Schwarzkopf R, Gupta R, et al. The perioperative surgical home as a future perioperative practice model. Anesth Analg. 2014;118:1126-30.

29. Garson L, Schwartzkopf R, Vakharia S, Alexander B, Stead S, Cannesson M, et al. Implementation of a total joint replacementfocused perioperative surgical home: a management case report. Anesth Analg. 2014;118:1081-9.

30. Le Manach Y, Hofer CK, Lehot JJ, Vallet B, Goarin JP, Tavernier B, et al. Can changes in arterial pressure be used to detect changes in cardiac output during volume expansion in the perioperative period? Anesthesiology. 2012;117:1165-74.

31. Peyton PJ, Chong SW. Minimally invasive measurement of cardiac output during surgery and critical care: a meta-analysis of accuracy and precision. Anesthesiology. 2010;113:1220-35.

32. Critchley LA, Critchley JA. A meta-analysis of studies using bias and precision statistics to compare cardiac output measurement techniques. J Clin Monit Comput. 1999;15:85-91.

33. Bein B, Renner J, Scholz J, Tonner PH. Comparing different methods of cardiac output determination: a call for consensus. Eur J Anaesthesiol. 2006;23:710.

34. Linton NW, Linton RA. Is comparison of changes in cardiac output, assessed by different methods, better than only 
comparing cardiac output to the reference method? Br J Anaesth. 2002;89:336-7.

35. Stetz CW, Miller RG, Kelly GE, Raffin TA. Reliability of the thermodilution method in the determination of cardiac output in clinical practice. Am Rev Respir Dis. 1982;126:1001-4.

36. Nilsson LB, Nilsson JC, Skovgaard LT, Berthelsen PG. Thermodilution cardiac output-are three injections enough? Acta Anaesthesiol Scand. 2004;48:1322-7.

37. Nishikawa T, Dohi S. Errors in the measurement of cardiac output by thermodilution. Can J Anaesth. 1993;40:142-53.

38. Practice guidelines for pulmonary artery catheterization: an updated report by the American Society of Anesthesiologists Task Force on Pulmonary Artery Catheterization. Anesthesiology. 2003;99:988-1014.

39. Bonazzi M, Gentile F, Biasi GM, Migliavacca S, Esposti D, Cipolla M, et al. Impact of perioperative haemodynamic monitoring on cardiac morbidity after major vascular surgery in low risk patients. A randomised pilot trial. Eur J Vasc Endovasc Surg. 2002;23:445-51.

40. Chittock DR, Dhingra VK, Ronco JJ, Russell JA, Forrest DM, Tweeddale M, et al. Severity of illness and risk of death associated with pulmonary artery catheter use. Crit Care Med. 2004;32:911-5.

41. Connors AF Jr, Speroff T, Dawson NV, Thomas C, Harrell FE Jr, Wagner D, et al. The effectiveness of right heart catheterization in the initial care of critically ill patients. SUPPORT investigators. JAMA. 1996;276:889-97.

42. Harvey S, Harrison DA, Singer M, Ashcroft J, Jones CM, Elbourne D, et al. Assessment of the clinical effectiveness of pulmonary artery catheters in management of patients in intensive care (PAC-Man): a randomised controlled trial. Lancet. 2005;366:472-7.

43. Sandham JD, Hull RD, Brant RF, Knox L, Pineo GF, Doig CJ, et al. A randomized, controlled trial of the use of pulmonaryartery catheters in high-risk surgical patients. N Engl J Med. 2003;348:5-14.

44. Yu DT, Platt R, Lanken PN, Black E, Sands KE, Schwartz JS, et al. Relationship of pulmonary artery catheter use to mortality and resource utilization in patients with severe sepsis. Crit Care Med. 2003;31:2734-41.

45. Montenij LJ, de Waal EE, Buhre WF. Arterial waveform analysis in anesthesia and critical care. Curr Opin Anaesthesiol. 2011;24:651-6.

46. Mayer J, Boldt J, Poland R, Peterson A, Manecke GR Jr. Continuous arterial pressure waveform-based cardiac output using the FloTrac/Vigileo: a review and meta-analysis. J Cardiothorac Vasc Anesth. 2009;23:401-6.

47. Bendjelid K, Romand JA. Fluid responsiveness in mechanically ventilated patients: a review of indices used in intensive care. Intensive Care Med. 2003;29:352-60.

48. Marik PE, Baram M, Vahid B. Does central venous pressure predict fluid responsiveness? A systematic review of the literature and the tale of seven mares. Chest. 2008;134:172-8.

49. Pinsky MR, Teboul JL. Assessment of indices of preload and volume responsiveness. Curr Opin Crit Care. 2005;11:235-9.

50. Rex S, Brose S, Metzelder S, Huneke R, Schalte G, Autschbach $\mathrm{R}$, et al. Prediction of fluid responsiveness in patients during cardiac surgery. Br J Anaesth. 2004;93:782-8.

51. Wiesenack C, Fiegl C, Keyser A, Prasser C, Keyl C. Assessment of fluid responsiveness in mechanically ventilated cardiac surgical patients. Eur J Anaesthesiol. 2005;22:658-65.

52. Cannesson M, Le Manach Y, Hofer CK, Goarin JP, Lehot JJ, Vallet B, et al. Assessing the diagnostic accuracy of pulse pressure variations for the prediction of fluid responsiveness: a "gray zone" approach. Anesthesiology. 2011;115:231-41.
53. Cannesson M, Musard H, Desebbe O, Boucau C, Simon R, Henaine $\mathrm{R}$, et al. The ability of stroke volume variations obtained with Vigileo/FloTrac system to monitor fluid responsiveness in mechanically ventilated patients. Anesth Analg. 2009;108:513-7.

54. Suehiro K, Okutani R. Stroke volume variation as a predictor of fluid responsiveness in patients undergoing one-lung ventilation. J Cardiothorac Vasc Anesth. 2010;24:772-5.

55. Suehiro K, Okutani R. Influence of tidal volume for stroke volume variation to predict fluid responsiveness in patients undergoing one-lung ventilation. J Anesth. 2011;25:777-80.

56. Suehiro K, Rinka H, Ishikawa J, Fuke A, Arimoto H, Miyaichi T. Stroke volume variation as a predictor of fluid responsiveness in patients undergoing airway pressure release ventilation. Anaesth Intensive Care. 2012;40:767-72.

57. De Backer D, Pinsky MR. Can one predict fluid responsiveness in spontaneously breathing patients? Intensive Care Med. 2007;33:1111-3.

58. De Backer D, Heenen S, Piagnerelli M, Koch M, Vincent JL. Pulse pressure variations to predict fluid responsiveness: influence of tidal volume. Intensive Care Med. 2005;31:517-23.

59. Duperret S, Lhuillier F, Piriou V, Vivier E, Metton O, Branche $\mathrm{P}$, et al. Increased intra-abdominal pressure affects respiratory variations in arterial pressure in normovolaemice and hypovolaemic mechanically ventilated pigs. Intensive Care Med. 2007;33:163-71.

60. Marik PE, Levitov A, Young A, Andrews L. The use of bioreactance and carotid Doppler to determine volume responsiveness and blood flow redistribution following passive leg raising in hemodynamically unstable patients. Chest. 2013;143:364-70.

61. Marik PE. Noninvasive cardiac output monitors: a state-of theart review. J Cardiothorac Vasc Anesth. 2013;27:121-34.

62. Thom O, Taylor DM, Wolfe RE, Cade J, Myles P, Krum H, et al. Comparison of a supra-sternal cardiac output monitor (USCOM) with the pulmonary artery catheter. Br J Anaesth. 2009;103:800-4.

63. Chand R, Mehta Y, Trehan N. Cardiac output estimation with a new Doppler device after off-pump coronary artery bypass surgery. J Cardiothorac Vasc Anesth. 2006;20:315-9.

64. Cannesson M, Desebbe O, Rosamel P, Delannoy B, Robin J, Bastien $\mathrm{O}$, et al. Pleth variability index to monitor the respiratory variations in the pulse oximeter plethysmographic waveform amplitude and predict fluid responsiveness in the operating theatre. Br J Anaesth. 2008;101:200-6.

65. Loupec T, Nanadoumgar H, Frasca D, Petitpas F, Laksiri L, Baudouin D, et al. Pleth variability index predicts fluid responsiveness in critically ill patients. Crit Care Med. 2011;39:294-9.

66. Sandroni C, Cavallaro F, Marano C, Falcone C, De Santis P, Antonelli M. Accuracy of plethysmographic indices as predictors of fluid responsiveness in mechanically ventilated adults: a systematic review and meta-analysis. Intensive Care Med. 2012;38:1429-37.

67. Broch O, Bein B, Gruenewald M, Hocker J, Schottler J, Meybohm P, et al. Accuracy of the pleth variability index to predict fluid responsiveness depends on the perfusion index. Acta Anaesthesiol Scand. 2011;55:686-93.

68. Cannesson M, Delannoy B, Morand A, Rosamel P, Attof Y, Bastien $\mathrm{O}$, et al. Does the Pleth variability index indicate the respiratory-induced variation in the plethysmogram and arterial pressure waveforms? Anesth Analg. 2008;106:1189-94.

69. Monnet X, Picard F, Lidzborski E, Mesnil M, Duranteau J, Richard C, et al. The estimation of cardiac output by the Nexfin device is of poor reliability for tracking the effects of a fluid challenge. Crit Care. 2012;16:R212. 
70. Bogert LW, van Lieshout JJ. Non-invasive pulsatile arterial pressure and stroke volume changes from the human finger. Exp Physiol. 2005;90:437-46.

71. Chen G, Chung E, Meng L, Alexander B, Vu T, Rinehart J, et al. Impact of non invasive and beat-to-beat arterial pressure monitoring on intraoperative hemodynamic management. J Clin Monit Comput. 2012;26:133-40.

72. Ameloot K, Van De Vijver K, Van Regenmortel N, De Laet I, Schoonheydt K, Dits H, et al. Validation study of Nexfin ${ }^{\circledR}$ continuous non-invasive blood pressure monitoring in critically ill adult patients. Minerva Anestesiol. 2014 [Epub ahead of print].

73. Hofhuizen C, Lansdorp B, van der Hoeven JG, Scheffer GJ, Lemson J. Validation of noninvasive pulse contour cardiac output using finger arterial pressure in cardiac surgery patients requiring fluid therapy. J Crit Care. 2014;29:161-5.

74. Critchley LA, Calcroft RM, Tan PY, Kew J, Critchley JA. The effect of lung injury and excessive lung fluid, on impedance cardiac output measurements, in the critically ill. Intensive Care Med. 2000;26:679-85.

75. Raue W, Swierzy M, Koplin G, Schwenk W. Comparison of electrical velocimetry and transthoracic thermodilution technique for cardiac output assessment in critically ill patients. Eur J Anaesthesiol. 2009;26:1067-71.

76. Engoren M, Barbee D. Comparison of cardiac output determined by bioimpedance, thermodilution, and the Fick method. Am J Crit Care. 2005;14:40-5.

77. Marik PE, Pendelton JE, Smith R. A comparison of hemodynamic parameters derived from transthoracic electrical bioimpedance with those parameters obtained by thermodilution and ventricular angiography. Crit Care Med. 1997;25:1545-50.

78. Wang DJ, Gottlieb SS. Impedance cardiography: more questions than answers. Curr Cardiol Rep. 2006;8:180-6.

79. Raaijmakers E, Faes TJ, Scholten RJ, Goovaerts HG, Heethaar RM. A meta-analysis of three decades of validating thoracic impedance cardiography. Crit Care Med. 1999;27:1203-13.

80. Bowling LS, Sageman WS, O'Connor SM, Cole R, Amundson DE. Lack of agreement between measurement of ejection fraction by impedance cardiography versus radionuclide ventriculography. Crit Care Med. 1993;21:1523-7.

81. Waldron NH, Miller TE, Thacker JK, Manchester AK, White WD, Nardiello J, et al. A prospective comparison of a noninvasive cardiac output monitor versus esophageal Doppler monitor for goal-directed fluid therapy in colorectal surgery patients. Anesth Analg. 2014;118:966-75.

82. Marque S, Cariou A, Chiche JD, Squara P. Comparison between Flotrac-Vigileo and Bioreactance, a totally noninvasive method for cardiac output monitoring. Crit Care. 2009;13:R73.

83. Squara P, Denjean D, Estagnasie P, Brusset A, Dib JC, Dubois C. Noninvasive cardiac output monitoring (NICOM): a clinical validation. Intensive Care Med. 2007;33:1191-4.

84. Karpman VL. The theoretical analysis of Fick's equation. On the centennial of the use of Fick's principle in physiology. Z Kardiol. 1975;64:801-8.

85. Kotake Y, Yamada T, Nagata H, Suzuki T, Serita R, Katori N, et al. Improved accuracy of cardiac output estimation by the partial $\mathrm{CO}_{2}$ rebreathing method. J Clin Monit Comput. 2009;23:149-55.

86. Reinhart K, Kuhn HJ, Hartog C, Bredle DL. Continuous central venous and pulmonary artery oxygen saturation monitoring in the critically ill. Intensive Care Med. 2004;30:1572-8.

87. Ladakis C, Myrianthefs P, Karabinis A, Karatzas G, Dosios T, Fildissis G, et al. Central venous and mixed venous oxygen saturation in critically ill patients. Respiration. 2001;68:279-85.

88. Chawla LS, Zia H, Gutierrez G, Katz NM, Seneff MG, Shah M. Lack of equivalence between central and mixed venous oxygen saturation. Chest. 2004;126:1891-6.
89. Edwards JD, Mayall RM. Importance of the sampling site for measurement of mixed venous oxygen saturation in shock. Crit Care Med. 1998;26:1356-60.

90. Reinhart K, Rudolph T, Bredle DL, Hannemann L, Cain SM. Comparison of central-venous to mixed-venous oxygen saturation during changes in oxygen supply/demand. Chest. 1989;95:1216-21.

91. Rivers E. Mixed vs central venous oxygen saturation may be not numerically equal, but both are still clinically useful. Chest. 2006;129:507-8.

92. Collaborative Study Group on Perioperative $\mathrm{ScvO}_{2}$ Monitoring. Multicentre study on peri- and postoperative central venous oxygen saturation in high-risk surgical patients. Crit Care. 2006;10:R158.

93. $\bullet$ A Randomized Trial of Protocol-Based Care for Early Septic Shock. N Engl J Med. 2014. Yealy et al. conducted the multicenter, randomized Protocolized Care for Early Septic Shock (ProCESS) trial at 31 hospitals in the United States and revealed that protocol-based GDT including the use of $\mathrm{ScvO}_{2}$ did not improve the outcomes in septic patients.

94. Vallee F, Vallet B, Mathe O, Parraguette J, Mari A, Silva S, et al. Central venous-to-arterial carbon dioxide difference: an additional target for goal-directed therapy in septic shock? Intensive Care Med. 2008;34:2218-25.

95. Futier E, Robin E, Jabaudon M, Guerin R, Petit A, Bazin JE, et al. Central venous $\mathrm{O}(2)$ saturation and venous-to-arterial $\mathrm{CO}(2)$ difference as complementary tools for goal-directed therapy during high-risk surgery. Crit Care. 2010;14:R193.

96. Bakker J, Vincent JL, Gris P, Leon M, Coffernils M, Kahn RJ. Veno-arterial carbon dioxide gradient in human septic shock. Chest. 1992;101:509-15.

97. Goldman S, Sutter F, Ferdinand F, Trace C. Optimizing intraoperative cerebral oxygen delivery using noninvasive cerebral oximetry decreases the incidence of stroke for cardiac surgical patients. Heart Surg Forum. 2004;7:E376-81.

98. van den Brand JG, Verleisdonk EJ, van der Werken C. Near infrared spectroscopy in the diagnosis of chronic exertional compartment syndrome. Am J Sports Med. 2004;32:452-6.

99. Ward KR, Ivatury RR, Barbee RW, Terner J, Pittman R, Filho IP, et al. Near infrared spectroscopy for evaluation of the trauma patient: a technology review. Resuscitation. 2006;68:27-44.

100. Murkin JM, Adams SJ, Novick RJ, Quantz M, Bainbridge D, Iglesias I, et al. Monitoring brain oxygen saturation during coronary bypass surgery: a randomized, prospective study. Anesth Analg. 2007;104:51-8.

101. Slater JP, Guarino T, Stack J, Vinod K, Bustami RT, Brown JM, 3rd et al. Cerebral oxygen desaturation predicts cognitive decline and longer hospital stay after cardiac surgery. Ann Thorac Surg. 2009;87:36-44; discussion -5 .

102. Casati A, Fanelli G, Pietropaoli P, Proietti R, Tufano R, Danelli $\mathrm{G}$, et al. Continuous monitoring of cerebral oxygen saturation in elderly patients undergoing major abdominal surgery minimizes brain exposure to potential hypoxia. Anesth Analg. 2005;101: $740-7$.

103. Murkin JM, Arango M. Near-infrared spectroscopy as an index of brain and tissue oxygenation. Br J Anaesth. 2009;103(Suppl 1):i3-13.

104. Scheeren TW, Schober P, Schwarte LA. Monitoring tissue oxygenation by near infrared spectroscopy (NIRS): background and current applications. J Clin Monit Comput. 2012;26:279-87.

105. • Cecconi M, Corredor C, Arulkumaran N, Abuella G, Ball J, Grounds RM et al. Clinical review: Goal-directed therapy-what is the evidence in surgical patients? The effect on different risk groups. Crit Care. 2013;17:209. Cecconi et al. performed a meta-analysis investigating the effect of GDT on different risk groups, the mortality benefit of GDT was limited to the 
extremely high-risk group patients (odds ratio $=0.27,95 \%$ confidence interval 0.15 to $0.51, p<0.00001)$. Complication rates were reduced in all risk subgroups (odds ratio $=0.45$, $95 \%$ confidence interval 0.34 to $0.60, p<0.00001$ ).

106. Cannesson M, Manach YL. Noninvasive hemodynamic monitoring: no high heels on the farm; no clogs to the opera. Anesthesiology. 2012;117:937-9.

107. Ebm C, Cecconi M, Sutton L, Rhodes A. A cost-effectiveness analysis of postoperative goal-directed therapy for high-risk surgical patients. Crit Care Med. 2014;42:1194-203.

108. Forget P, Lois F, de Kock M. Goal-directed fluid management based on the pulse oximeter-derived pleth variability index reduces lactate levels and improves fluid management. Anesth Analg. 2010;111:910-4.

109. Campbell B. NICE medical technologies guidance: aims for clinical practice. Perioper Med. 2013;2:15.

110. Ramsingh DS, Sanghvi C, Gamboa J, Cannesson M, Applegate RL 2nd. Outcome impact of goal directed fluid therapy during high risk abdominal surgery in low to moderate risk patients: a randomized controlled trial. J Clin Monit Comput. 2013;27:249-57.

111. Lugo G, Arizpe D, Dominguez G, Ramirez M, Tamariz O. Relationship between oxygen consumption and oxygen delivery during anesthesia in high-risk surgical patients. Crit Care Med. 1993;21:64-9.

112. Shibutani K, Komatsu T, Kubal K, Sanchala V, Kumar V, Bizzarri DV. Critical level of oxygen delivery in anesthetized man. Crit Care Med. 1983;11:640-3.

113. Waxman K, Nolan LS, Shoemaker WC. Sequential perioperative lactate determination. Physiological and clinical implications. Crit Care Med. 1982;10:96-9.

114. Shoemaker WC, Appel PL, Kram HB. Tissue oxygen debt as a determinant of lethal and nonlethal postoperative organ failure. Crit Care Med. 1988;16:1117-20.

115. Shoemaker WC, Appel P, Bland R. Use of physiologic monitoring to predict outcome and to assist in clinical decisions in critically ill postoperative patients. Am J Surg. 1983;146:43-50.

116. Shoemaker WC, Appel PL, Kram HB. Role of oxygen debt in the development of organ failure sepsis, and death in high-risk surgical patients. Chest. 1992;102:208-15.

117. Lobo SM, Lobo FR, Polachini CA, Patini DS, Yamamoto AE, de Oliveira NE, et al. Prospective, randomized trial comparing fluids and dobutamine optimization of oxygen delivery in highrisk surgical patients. Crit Care. 2006;10:R72.

118. Bowdle TA. Complications of invasive monitoring. Anesthesiol Clin N Am. 2002;20:571-88.

119. Donati A, Loggi S, Preiser JC, Orsetti G, Munch C, Gabbanelli $\mathrm{V}$, et al. Goal-directed intraoperative therapy reduces morbidity and length of hospital stay in high-risk surgical patients. Chest. 2007;132:1817-24.

120. Pearse R, Dawson D, Fawcett J, Rhodes A, Grounds RM, Bennett ED. Changes in central venous saturation after major surgery, and association with outcome. Crit Care. 2005;9:R694-9.

121. Vallet B, Futier E, Robin E. Tissue oxygenation parameters to guide fluid therapy. Transfus Altern Transfus Med. 2010;11:113-7.

122. Rinehart J, Alexander B, Le Manach Y, Hofer C, Tavernier B, Kain ZN, et al. Evaluation of a novel closed-loop fluid-administration system based on dynamic predictors of fluid responsiveness: an in silico simulation study. Crit Care. 2011;15:R278.
123. Rinehart J, Chung E, Canales C, Cannesson M. Intraoperative stroke volume optimization using stroke volume, arterial pressure, and heart rate: closed-loop (learning intravenous resuscitator) versus anesthesiologists. J Cardiothorac Vasc Anesth. 2012;26:933-9.

124. Rinehart J, Lee C, Cannesson M, Dumont G. Closed-loop fluid resuscitation: robustness against weight and cardiac contractility variations. Anesth Analg. 2013;117:1110-8.

125. Rinehart J, Lee C, Canales C, Kong A, Kain Z, Cannesson M. Closed-loop fluid administration compared to anesthesiologist management for hemodynamic optimization and resuscitation during surgery: an in vivo study. Anesth Analg. 2013;117:1119-29.

126. Rinehart J, Le Manach Y, Douiri H, Lee C, Lilot M, Le K et al. First closed-loop goal directed fluid therapy during surgery: a pilot study. Ann Fr Anesth Reanim. 2013. 33(2):138-43.

127. Murakawa K, Kobayashi A. Effects of vasopressors on renal tissue gas tensions during hemorrhagic shock in dogs. Crit Care Med. 1988;16:789-92.

128. Rosenberg AL, Dechert RE, Park PK, Bartlett RH. Review of a large clinical series: association of cumulative fluid balance on outcome in acute lung injury: a retrospective review of the ARDSnet tidal volume study cohort. J Intensive Care Med. 2009;24:35-46.

129. Chappell D, Jacob M, Hofmann-Kiefer K, Conzen P, Rehm M. A rational approach to perioperative fluid management. Anesthesiology. 2008;109:723-40.

130. Benes J, Chytra I, Altmann P, Hluchy M, Kasal E, Svitak R, et al. Intraoperative fluid optimization using stroke volume variation in high risk surgical patients: results of prospective randomized study. Crit Care. 2010;14:R118.

131. Scheeren TW, Wiesenack C, Gerlach H, Marx G. Goal-directed intraoperative fluid therapy guided by stroke volume and its variation in high-risk surgical patients: a prospective randomized multicentre study. J Clin Monit Comput. 2013;27:225-33.

132. Zheng H, Guo H, Ye JR, Chen L, Ma HP. Goal-directed fluid therapy in gastrointestinal surgery in older coronary heart disease patients: randomized trial. World J Surg. 2013;37:2820-9.

133. Lopes MR, Oliveira MA, Pereira VO, Lemos IP, Auler JO Jr, Michard F. Goal-directed fluid management based on pulse pressure variation monitoring during high-risk surgery: a pilot randomized controlled trial. Crit Care. 2007;11:R100.

134. Salzwedel C, Puig J, Carstens A, Bein B, Molnar Z, Kiss K, et al. Perioperative goal-directed hemodynamic therapy based on radial arterial pulse pressure variation and continuous cardiac index trending reduces postoperative complications after major abdominal surgery: a multi-center, prospective, randomized study. Crit Care. 2013;17:R191.

135. Conway DH, Mayall R, Abdul-Latif MS, Gilligan S, Tackaberry C. Randomised controlled trial investigating the influence of intravenous fluid titration using oesophageal Doppler monitoring during bowel surgery. Anaesthesia. 2002;57:845-9.

136. Buettner M, Schummer W, Huettemann E, Schenke S, van Hout N, Sakka SG. Influence of systolic-pressure-variation-guided intraoperative fluid management on organ function and oxygen transport. Br J Anaesth. 2008;101:194-9. 